\title{
The different stages of PRPD pattern for negative point to plane corona driven by a DC voltage containing a ripple
}

Tobias Dezenzo

Technological University Dublin

Thomas Betz

Darmstadt University of Applied Sciences

Andreas Schwarzbacher

Technological University Dublin, andreas.schwarzbacher@tudublin.ie

Follow this and additional works at: https://arrow.tudublin.ie/engscheleart2

Part of the Electrical and Computer Engineering Commons

\section{Recommended Citation}

T. Dezenzo, T. Betz and A. Schwarzbacher, "The different stages of PRPD pattern for negative point to plane corona driven by a DC voltage containing a ripple," in IEEE Transactions on Dielectrics and Electrical Insulation, vol. 24, no. 1, pp. 47-53, Feb. 2017, doi: 10.1109/TDEI.2016.005897.

This Article is brought to you for free and open access by the School of Electrical and Electronic Engineering at ARROW@TU Dublin. It has been accepted for inclusion in Articles by an authorized administrator of ARROW@TU Dublin. For more information, please contact arrow.admin@tudublin.ie, aisling.coyne@tudublin.ie, gerard.connolly@tudublin.ie.

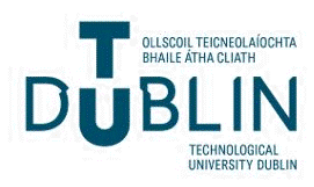




\title{
The Different Stages of PRPD Pattern for Negative Point to Plane Corona Driven by a DC Voltage Containing a Ripple
}

\author{
Tobias Dezenzo $^{1,2}$, Thomas Betz ${ }^{1}$ and Andreas Schwarzbacher ${ }^{2}$ \\ ${ }^{1}$ Darmstadt University of Applied Sciences \\ Birkenweg 8 \\ 64295 Darmstadt, Germany \\ ${ }^{2}$ Dublin Institute of Technology \\ Kevin Street \\ Dublin 8, Ireland
}

\begin{abstract}
This paper presents the different patterns, which can be observed by means of a phase resolved partial discharge analysis, when a negative de voltage is applied to a point to plane arrangement in air. The required phase relation is obtained due to the ripple being present on the dc voltage generated by a half-wave rectification. Phase resolved partial discharge patterns are given from corona onset to glow inception. Discharge pulses appearing at the test object are used to support physical explanations of the pattern occurrence. It is shown that five clearly identifiable patterns accompany the evolution of corona discharges when a de voltage with a ripple is used. The uniqueness of the different patterns and the accompanied reduction in test effort for dc partial discharges is emphasized.

Index Terms - Partial discharges, Ripple, HVDC, PRPD, Corona, Glow discharges, pattern.
\end{abstract}

\section{INTRODUCTION}

Partial discharges (PD) especially under direct voltage conditions are the topic of many research projects, e.g. $[1,2]$. Progress has been made to understand the general discharge behavior for internal PD [3] as well as the stress conditions leading to failure in HVDC equipment [4]. However, no agreed standard in discharge evaluation under dc conditions exists.

For dc PD diagnosis two different evaluation philosophies are currently being pursued. One is based on the physical properties of the discharge pulses e.g. [5] and the other one relies on the two available properties after charge integration, namely the discharge magnitude and the time of discharge occurrence [6]. Furthermore, combined approaches have been proposed [7]. All of the methods rely on post-processing or complex statistical treatment of the measured quantities and are thus not solely based on the measured data. Therefore, commercially available PD measuring devices and software for ac PD cannot directly be adapted for dc PD purposes. Hence, an evaluation method for dc PD has been introduced $[8,9]$, which is based on the popular phase resolved partial discharge (PRPD) representation well-known from ac PD. The advantage of PRPD is the uniqueness and reproducibility

Manuscript received on 26 February 2016, in final form 6 July 2016, accepted 14 July 2016. of pattern appearance of different defects e.g. corona, internal or surface PD.

As a phase resolved evaluation requires a repeating sequence the dc signal has to be modified, whereas the modification must not change or significantly influence the general discharge behavior.

For negative corona discharges with a repeating sequence being present due to the ripple of a negative half-wave rectification it could be shown that if the ripple is small enough, the corona has a unique pattern, while maintaining the general discharge properties [9].

To distinguish between different types of PD by means of PRPD the possible pattern appearance, being influenced by the source of PD, has to be known. As PD is an effect which is driven by voltage it is important to know how the different patterns being caused by the various defect types evolve with voltage.

This paper presents the different possible patterns for corona being triggered by a dc voltage combined with a ripple caused by negative half-wave rectification.

\section{MEASUREMENT SETUP}

\subsection{CIRCUIT AND DEVICES}

The measurements are performed in accordance with IEC 60270. The equivalent circuit of the test setup is shown in Figure 1. Energy supply is made via an ac source combined with a high voltage transformer. The coupling capacitance $C_{k l}$ 
is used to synchronize the PD detection with the $50 \mathrm{~Hz}$ ac sinusoid. $C_{1}$ serves as the high voltage part of a voltage divider to measure the applied ac voltage. The inductance $L$ is used to decouple the net from the PD source during discharge activity. The diodes are responsible for the negative half-wave rectification. Two diodes are used in series to reduce the individual voltage drop per diode, leading to an enhanced overall voltage drop.

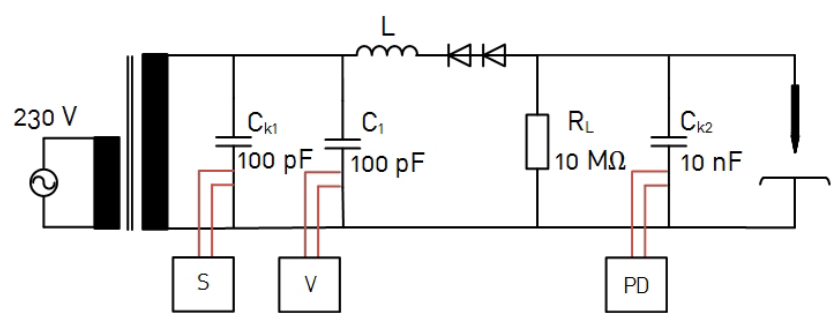

Figure 1. Equivalent circuit of the measuring setup for needle-plate configuration including the devices for synchronization $S$, voltage measurement $V$ and partial discharge decoupling $P D$.

The ripple of the dc voltage can be adjusted with the load resistor $R_{L}$ due to its influence on the time constant of the circuit. A lower time constant for example means that more energy is taken out of the capacitor. More energy leads to a higher voltage drop and hence to an increased ripple on the dc voltage. If an almost pure dc voltage is desired, than the load resistor is omitted. It has to be kept in mind that the ripple cannot be zero due to the on-resistance of the diodes. The capacitance $\mathrm{C}_{\mathrm{k} 2}$ is used to decouple the PD signal and to smooth the signal.

The partial discharges as well as the ac voltage are recorded with a MPD 600 manufactured by OMICRON. The dc voltage is measured via a field mill to ensure that the dc side of the circuit is not influenced through a voltage divider. The MPD itself is not able to measure dc voltages without modifications to the device. Voltage values are always related to the de voltage measured via the field mill. The ripple, which is an ac signal, is also recorded with the PD measuring system. An oscilloscope (Agilent InfiniiVision MSO-X-3014A) with $100 \mathrm{MHz}$ bandwidth and up to $4 \mathrm{GSa} / \mathrm{s}$ is used to measure the PD pulses appearing at the test-object. The pulses are measured using an $1 \mathrm{k} \Omega$ shunt resistor connected in series to the test object.

\subsection{SELECTION OF THE RIPPLE}

The tests were carried out in air with an electrode interspacing of $30 \mathrm{~mm}$ and a voltage range from $-20 \mathrm{kV}$ (slightly above the inception voltage) to $-36 \mathrm{kV}$ (slightly above glow inception voltage). The tip radius of the needle is about $0.5 \mathrm{~mm}$ and the plate is rogowski-shaped. The tests were performed at $20{ }^{\circ} \mathrm{C}$ with a relative humidity of about $30 \%$ and at a pressure of 1 bar. For comparison reasons measurements were also performed using an almost pure dc voltage with a ripple smaller than $0.05 \%$.

The load resistor is chosen to be $10 \mathrm{M} \Omega$ and in combination with $\mathrm{C}_{\mathrm{k} 2}$ being $10 \mathrm{nF}$ results in a ripple of about $7.5 \%$ i.e. $-1.5 \mathrm{kV}$ peak at $-20 \mathrm{kV}$ dc voltage. This ripple in fact is very high compared to the requirements of common HVDC applications but variations of the ripple showed that $7.5 \%$ is about the amount required to have a visible effect, by means of PRPD, on the pattern through the whole voltage range. The visibility is caused by the voltage dependence of the corona discharges. A smaller ripple results in the loss of this triggering mechanism and therefore is not applicable at voltages highly above the inception voltage.

For tests closely above the inception voltage a ripple of about $0.25 \%$ is sufficient to identify a PD source as corona via pattern recognition. This is indicated in Figure 2, where the discharge magnitude dependence on the applied voltage can clearly be observed.

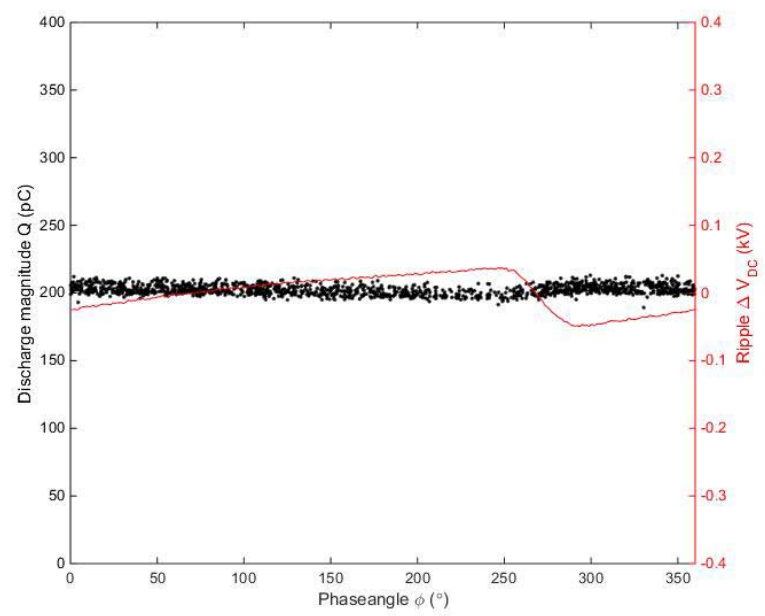

Figure 2. $\mathrm{Q}(\phi)$ and $\Delta \mathrm{V}_{\mathrm{DC}}(\phi)$ for a needle-plate arrangement with $30 \mathrm{~mm}$ electrode interspacing at $-19.3 \mathrm{kV}$ dc with a ripple of $0.25 \%$.

\section{PRESENTATION OF THE DATA}

The results are presented using three different types of diagrams. These are:

1) $\mathrm{Q}(\phi)$-diagram, which displays the recorded discharge magnitude over the phase angle of the applied voltage. The applied voltage is presented without its dc component i.e. only its ripple is shown.

2) PD pulses as a function of time. The corresponding diagrams show the pulses as they are recorded through the oscilloscope and are referred to as currents in this paper. Focus is placed on the amount of discharges and the point of occurrence rather than on the amplitude. In general the corona current is proportional to the applied voltage, therefore pulses and voltage can easily be correlated.

3) Q(t)-diagram, where the discharge magnitude is plotted over the time of occurrence. These figures do additionally contain the applied voltage in an unscaled form.

\section{RESULTS AND DISCUSSION}

At $-20 \mathrm{kV}$ dc the voltage is slightly above the inception voltage as shown in the $\mathrm{Q}(\phi)$-diagram in Figure 3. The discharges are scattered around the maximum of the applied voltage. These discharges form the first pattern to be observed 
when a dc voltage with a ripple is used. Hence PD inception for corona discharges can be identified as a concentration of discharges in the maximum of the applied voltage.

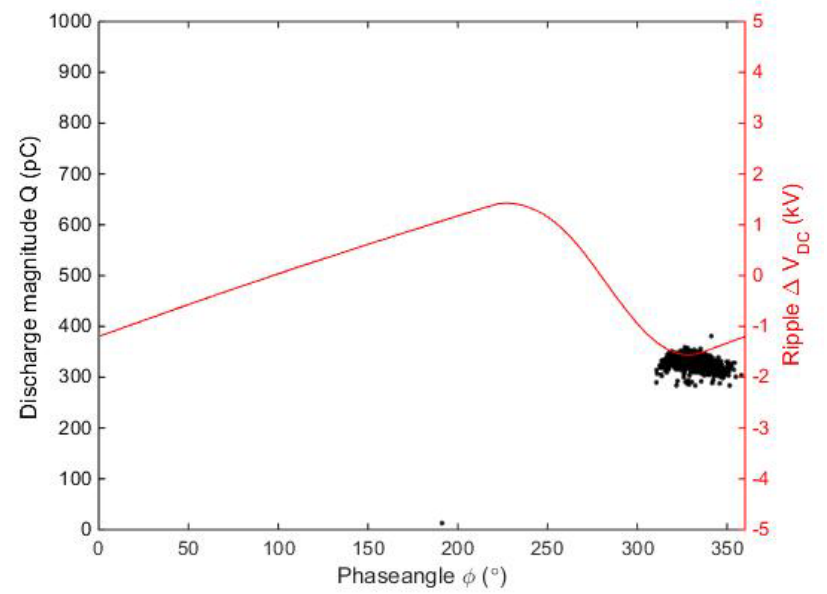

Figure 3. $Q(\phi)$ and $\Delta V_{D C}(\phi)$ for a needle-plate arrangement with $30 \mathrm{~mm}$ electrode interspacing at $-20 \mathrm{kV}$ dc with a ripple of $7.5 \%$.

If the dc voltage is further increased discharges occur over a broader part, with respect to the phase angle, of the voltage curve (Figure 4). The broadening of the pattern can be explained with the inception voltage which has to be reached to start ionization processes governed by the Townsend mechanism. If the inception voltage is not reached no ionization takes place. Hence, no discharges are encountered at the related phase angle, which is in accordance with the pulses appearing at the test object (Figure 5). Additionally, as the voltage is enhanced the field strength is increased resulting in a reduced required free path for ionization [10], leading to more ionizations accompanied by higher discharge pulses and an enhanced ion mobility and thus a higher discharge frequency (Figure 6) by faster ion dissipation. The latter was shown by means of a numerical simulation [11].

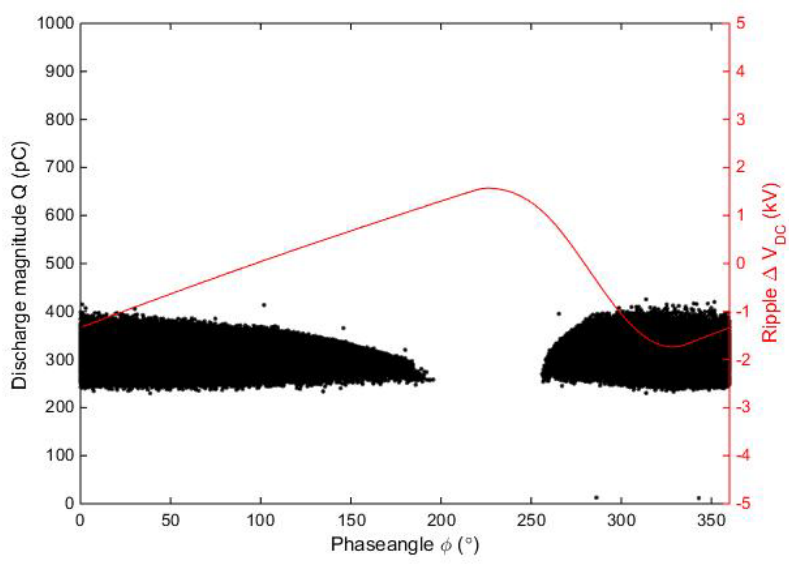

Figure 4. $\mathrm{Q}(\phi)$ and $\Delta \mathrm{V}_{\mathrm{DC}}(\phi)$ for a needle-plate arrangement with $30 \mathrm{~mm}$ electrode interspacing at $-22.1 \mathrm{kV}$ dc with a ripple of $7.5 \%$.

An evaluation of the inception voltage through-out pattern-build up results in a constant inception voltage of about $-21 \mathrm{kV}$. If the inception voltage is reached throughout the whole course of the voltage curve i.e. $-21 \mathrm{kV}$ in the negative extremum, then the resulting dc voltage is $-22.7 \mathrm{kV}$ at a ripple of $7.5 \%$. The pattern then reaches from $0^{\circ}$ to $360^{\circ}$ where the highest discharge magnitude can be observed during the maximum of the applied voltage comparable to Figure 2.

In the case present the inception voltage was found to be -21 $\mathrm{kV}$ which is not in accordance with the pure dc case, where the voltage was about $-19.5 \mathrm{kV}$, due to the accuracy of the field mill.

A further increase of the voltage results in a modification of the discharge pattern as per Figure 7 . The waveform of the voltage is then also present in the low discharge magnitude range $(200 \mathrm{pC})$, but showing an inverse proportionality. This can be used as a second identification attribute for corona discharges.

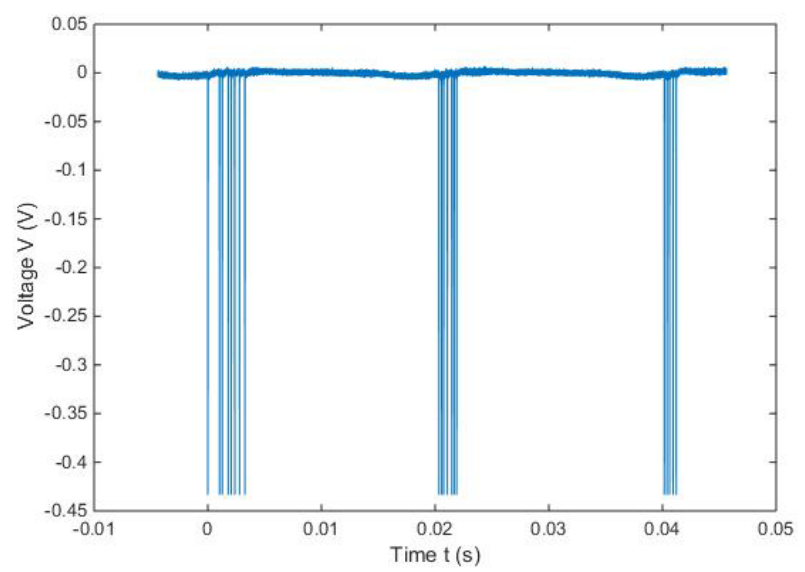

Figure 5. PD pulses recorded at the test object for a voltage of $-20 \mathrm{kV}$ dc with $7.5 \%$ ripple.

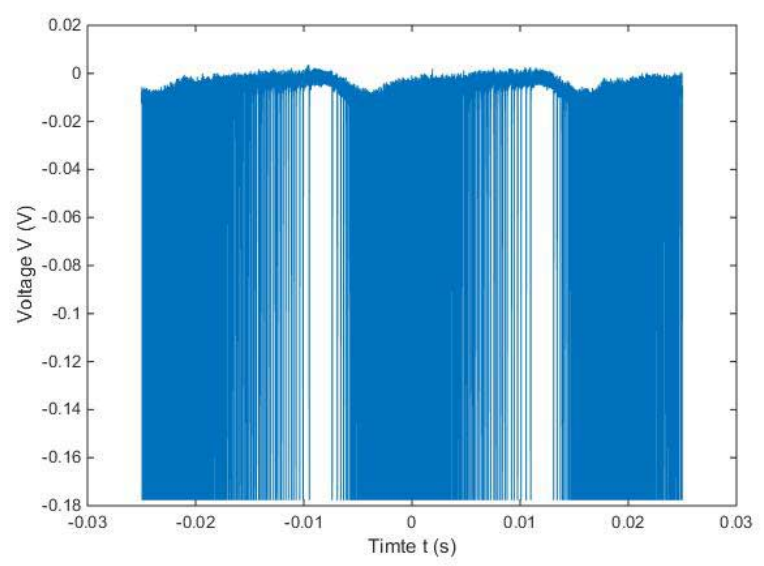

Figure 6. PD pulses recorded at the test object for a voltage of $-22.1 \mathrm{kV} \mathrm{dc}$ with $7.5 \%$ ripple.

At a voltage of $-26.7 \mathrm{kV}$ the phase resolved discharge representation shows a pattern that perfectly follows the course of the applied voltage in terms of its proportionality of the maximum discharge magnitude and inverse proportionality for the lowest occurring discharge magnitudes (Figure 8). No other properties are observed in the phase resolved representation, but a precise examination of the discharge magnitude versus time behavior indicates a drastic change as shown in Figure 9. The vertical lines in the figure clarify that the highest discharges are not always occurring in the maximum of the 
applied negative voltage, which is used as a reference, and if so are somehow split into two columns appearing left and right from the voltage maximum.

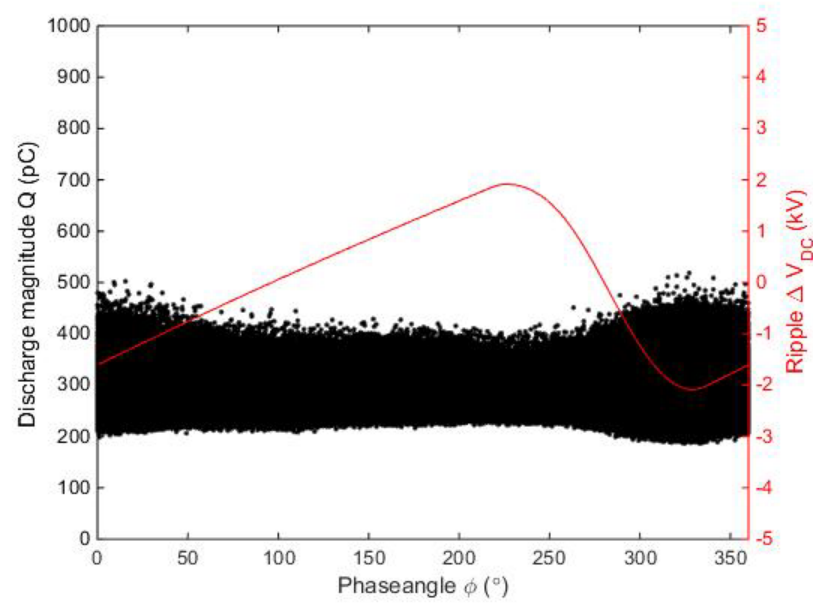

Figure 7. $\mathrm{Q}(\phi)$ and $\Delta \mathrm{V}_{\mathrm{DC}}(\phi)$ for a needle-plate arrangement with $30 \mathrm{~mm}$ electrode interspacing at $-26.4 \mathrm{kV}$ dc with a ripple of $7.5 \%$.

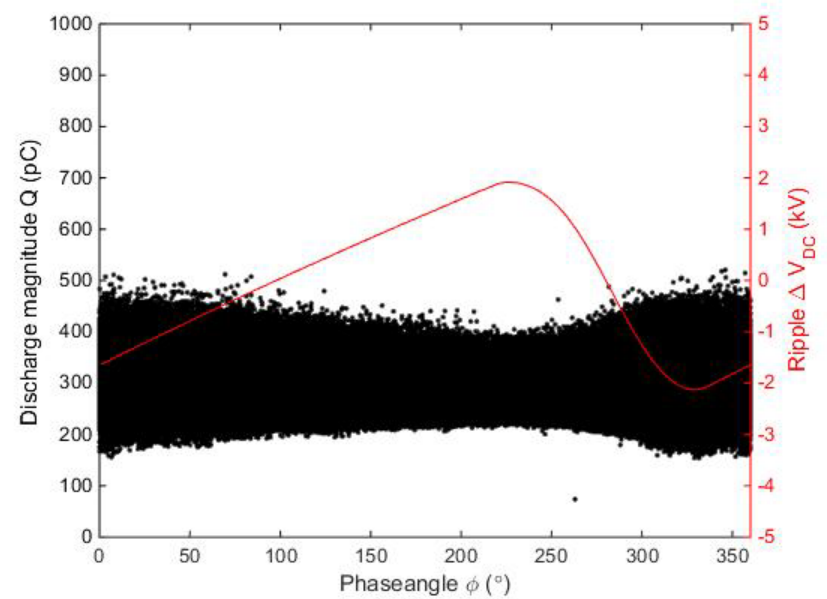

Figure 8. $\mathrm{Q}(\phi)$ and $\Delta \mathrm{V}_{\mathrm{DC}}(\phi)$ for a needle-plate arrangement with $30 \mathrm{~mm}$ electrode interspacing at $-26.7 \mathrm{kV} \mathrm{dc}$ with a ripple of $7.5 \%$.

An investigation of the discharge pulses at the test object (Figure 10) shows pulses with remarkably low starting currents in the area of the voltage maximum, where low is defined with respect to the negative nature of the pulses. The very low starting point leads to very high discharge magnitudes, as the current pulses are integrated to form the apparent charge, which is here represented as discharge magnitude $Q$. Therefore, it is these pulses which lead to the consecutive maxima in the vicinity of the voltage maximum as per Figure 9. This behavior might be caused by the presence of positive space charges, which contribute to the discharges by releasing secondary electrons due to cathode bombardment, which will be strongest in the maximum of the applied voltage due to the increase in mobility and the enhanced ionization. The phenomenon can also be observed when a pure dc voltage is applied (Figure 11).

Another increase of the voltage leads to a more frequent occurrence of the forgoing effect for the 7.5\% ripple case as well as for the pure dc case. The low magnitude discharges, which become even lower for higher voltages
(Figure 12), might be caused due to the faster ion mobility. As discharges can only start after the negative ions have moved sufficiently far away [12], an increased mobility would on one hand increase the pulse frequency and on the other hand might lead to such a high frequency that the negative ions are not ceasing the development of a discharge but still influence the gap due to field reduction in a way that high discharge amplitudes cannot develop.

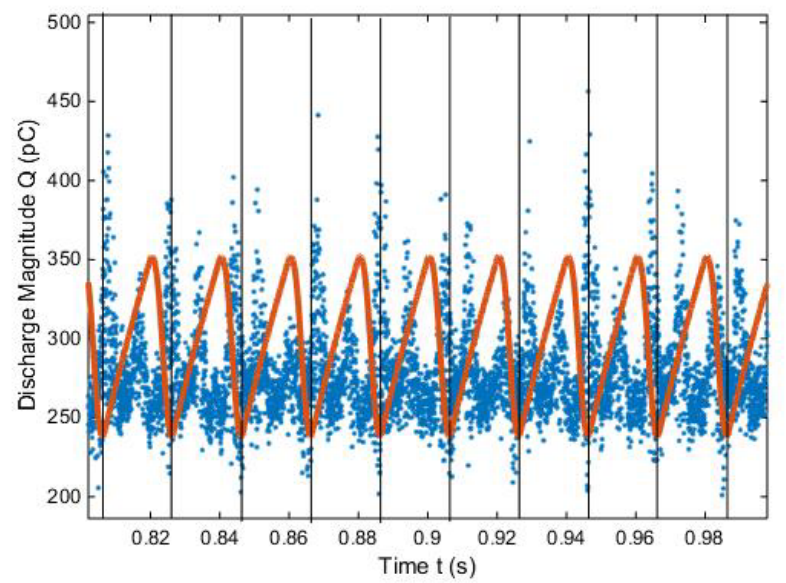

Figure 9. $\mathrm{Q}(\mathrm{t})$ and $\Delta \mathrm{V}_{\mathrm{DC}}(\phi)$ (unscaled) for a needle-plate arrangement with 30 mm electrode interspacing at $-26.7 \mathrm{kV} \mathrm{dc}$ with a ripple of $7.5 \%$.

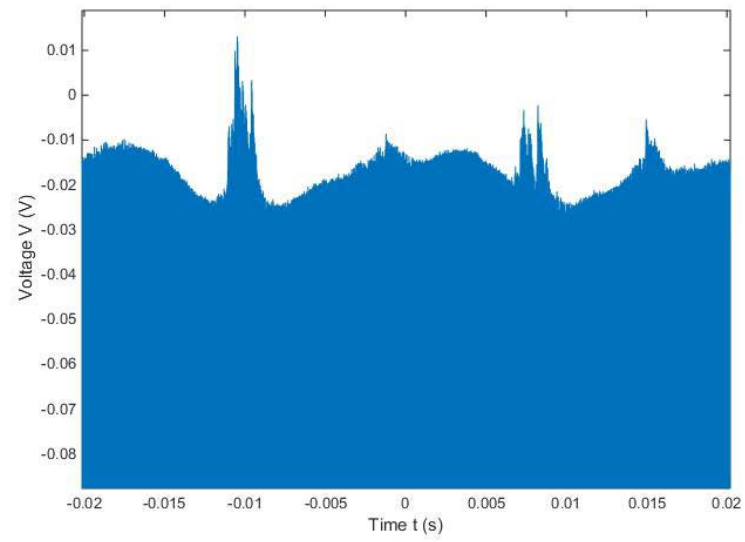

Figure 10. PD pulses recorded at the test object for a voltage of $-26.7 \mathrm{kV} \mathrm{dc}$ with $7.5 \%$ ripple.

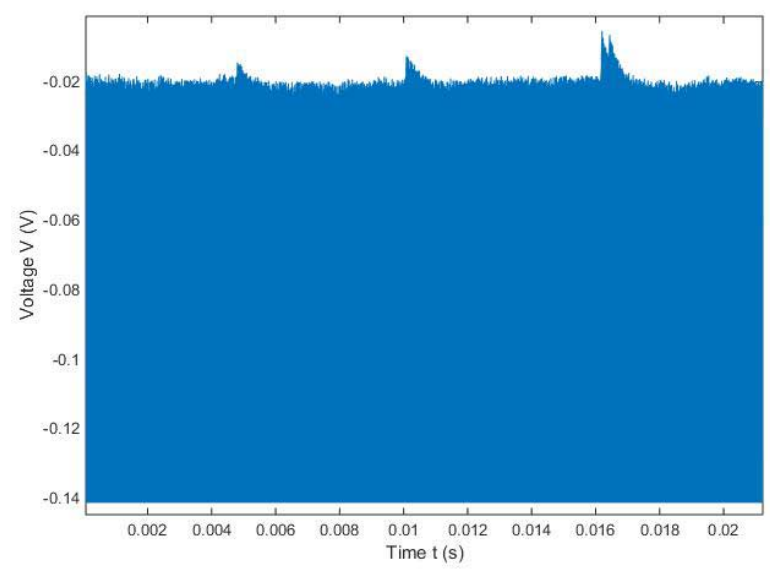

Figure 11. PD pulses recorded at the test object for a voltage of $-26.3 \mathrm{kV}$ dc with $0.05 \%$ ripple. 


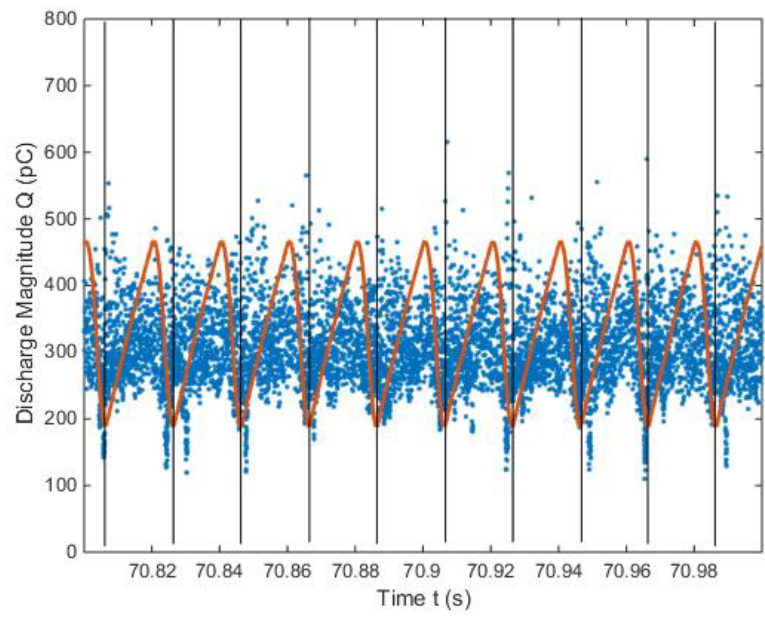

Figure 12. $\mathrm{Q}(\mathrm{t})$ and $\Delta \mathrm{V}_{\mathrm{DC}}(\phi)$ (unscaled) for a needle-plate arrangement with $30 \mathrm{~mm}$ electrode interspacing at $-28.3 \mathrm{kV}$ dc with a ripple of $7.5 \%$.

An examination of the pure dc case shows that the low discharge magnitudes are not an effect of the $50 \mathrm{~Hz}$ voltage ripple as they occur much more frequent and irregular (Figure 13).

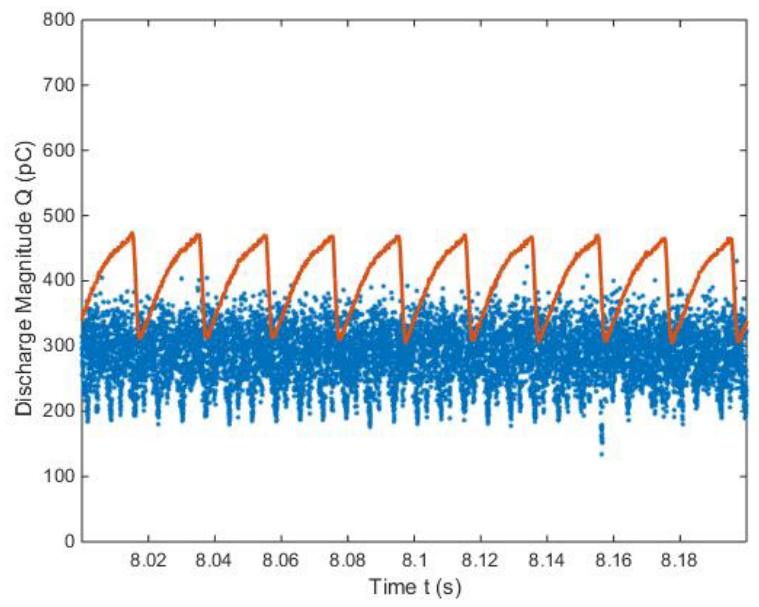

Figure 13. $\mathrm{Q}(\mathrm{t})$ and $\Delta \mathrm{V}_{\mathrm{DC}}(\phi)$ (unscaled) for a needle-plate arrangement with $30 \mathrm{~mm}$ electrode interspacing at $-28.0 \mathrm{kV}$ dc with a ripple of $0.05 \%$.

A further increase of the voltage leads to a shrinking of the pattern, which indicates the beginning transition from a Trichel pulse corona to a pulseless glow discharge. The magnitude reduction occurs again in the maximum of the applied voltage as indicated in Figure 14. The cause for this can again be found by analyzing the discharges that appear at the test object (Figure 15). The figure shows that the additional pulses are drastically reduced in the region of the maximum voltage.

Raising the voltage to $-33.6 \mathrm{kV}$ results in a $\mathrm{Q}(\phi)$ diagram as presented in Figure 16. The high discharge magnitudes are now inversely proportional to the waveform of the applied voltage. Figure 17 proofs that the low starting point current pulses were responsible for the high discharge magnitudes, which can now be observed near the minimum of the applied voltage.

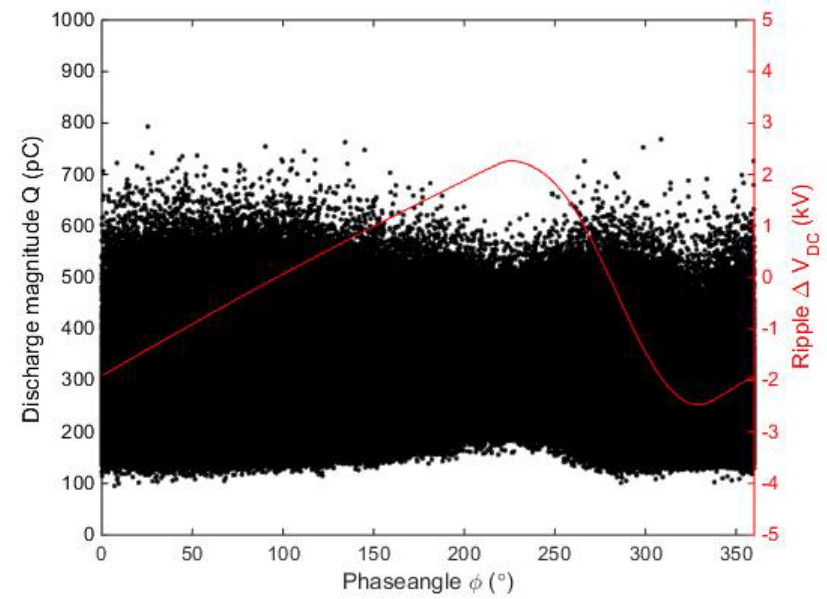

Figure 14. $\mathrm{Q}(\phi)$ and $\Delta \mathrm{V}_{\mathrm{DC}}(\phi)$ for a needle-plate arrangement with $30 \mathrm{~mm}$ electrode interspacing at $-30.4 \mathrm{kV}$ dc with a ripple of $7.5 \%$.

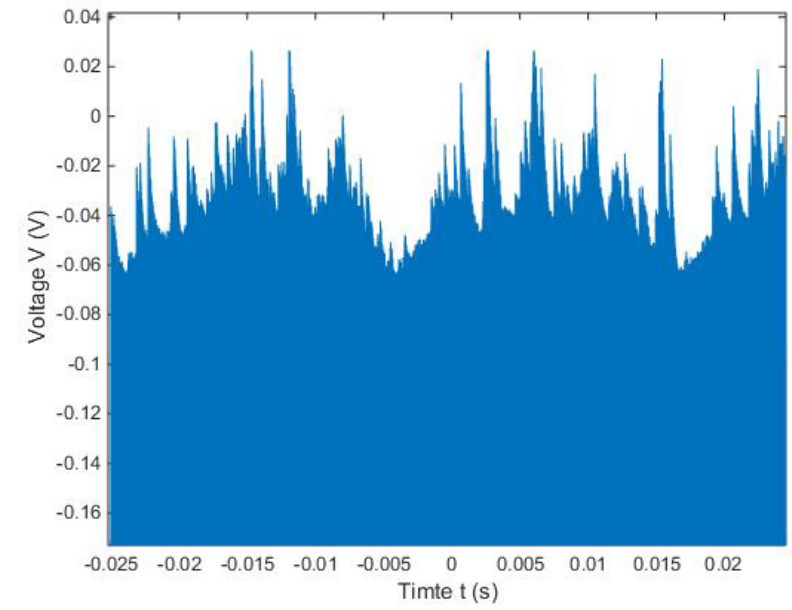

Figure 15. PD pulses recorded at the test object for a voltage of $-30.4 \mathrm{kV} d c$ with $7.5 \%$ ripple.

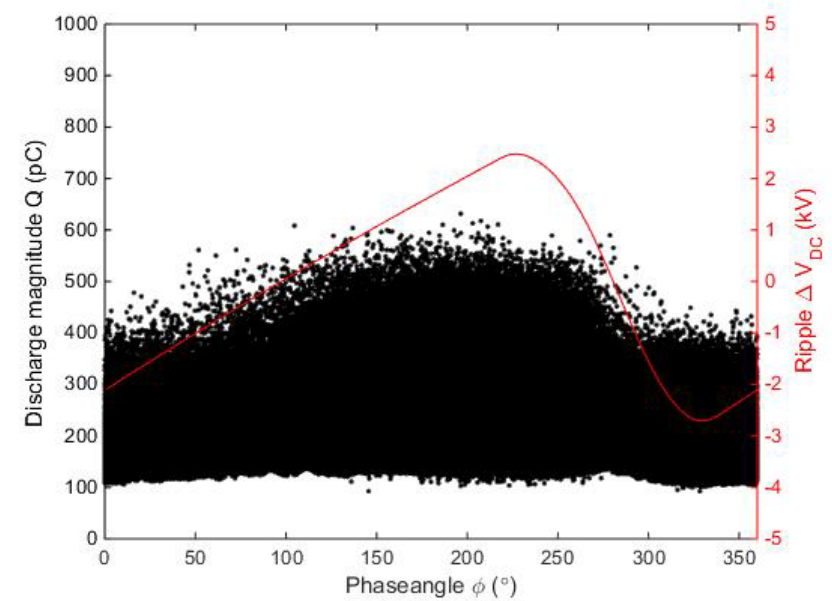

Figure 16. $\mathrm{Q}(\phi)$ and $\Delta \mathrm{V}_{\mathrm{DC}}(\phi)$ for a needle-plate arrangement with $30 \mathrm{~mm}$ electrode interspacing at $-33.6 \mathrm{kV}$ dc with a ripple of $7.5 \%$.

Finally, if the voltage is increased further the pulsating nature of the discharges stops, resulting in the occurrence of continuous glow discharges. This is a strongly space charge dependent process that cannot easily be recognized in the phase resolved pattern. That is because the phase resolved discharge 
analysis is performed by superimposing recorded discharge magnitudes and their phase angle of occurrence (related to the frequency of the voltage to which the recording is synchronized). Glow discharges show a constant current behavior and are hence, not evaluated as a partial discharge from the measuring device. Therefore, if glow discharges occur during one period of the synchronization and not at the same phase angle during the next cycle they might be hidden in the $\mathrm{Q}(\phi)$-diagram. However, they can be observed in a time series of discharges as per Figure 18 and are clearly evident from the discharge pulses at the testobject (Figure 19).

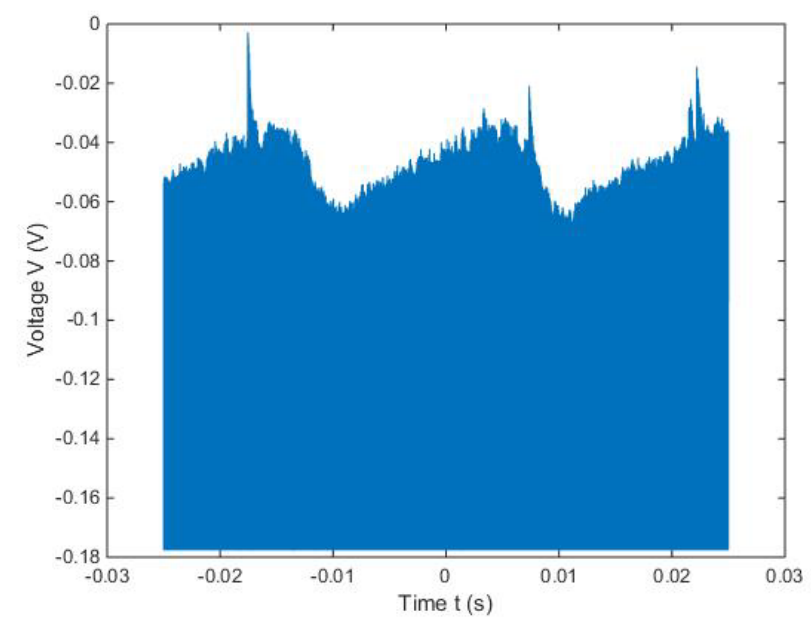

Figure 17. PD pulses recorded at the test object for a voltage of $-33.6 \mathrm{kV}$ dc with $7.5 \%$ ripple.

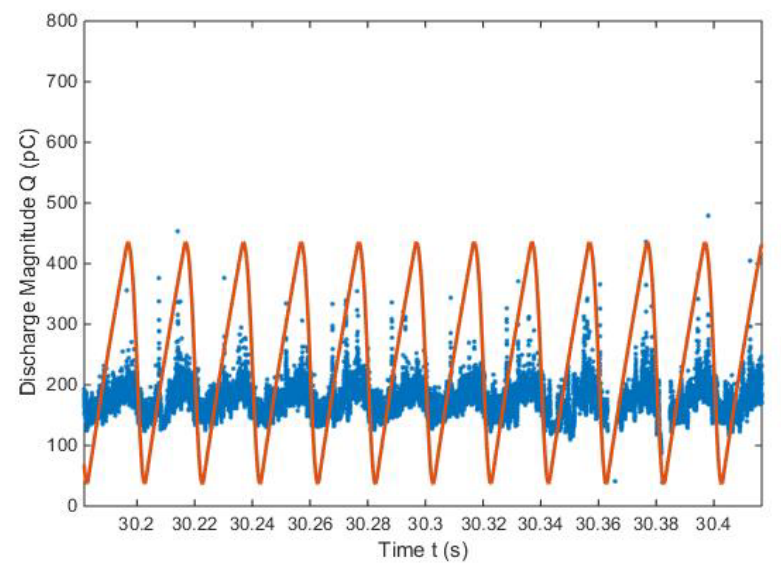

Figure 18. $\mathrm{Q}(\mathrm{t})$ and $\Delta \mathrm{V}_{\mathrm{DC}}(\phi)$ (unscaled) for a needle-plate arrangement with $30 \mathrm{~mm}$ electrode interspacing at $-36.3 \mathrm{kV}$ dc with a ripple of $7.5 \%$.

If the voltage is high enough then glow discharges can be present throughout larger segments of the curse of the voltage curve resulting in a pattern as can be seen in Figure 20. This pattern can easily be distinguished from the inception pattern shown in Figure 3 because here the discharges are only present in the minimum of the applied voltage and not in the maximum of the voltage whereas it is the other way around for the inception case.

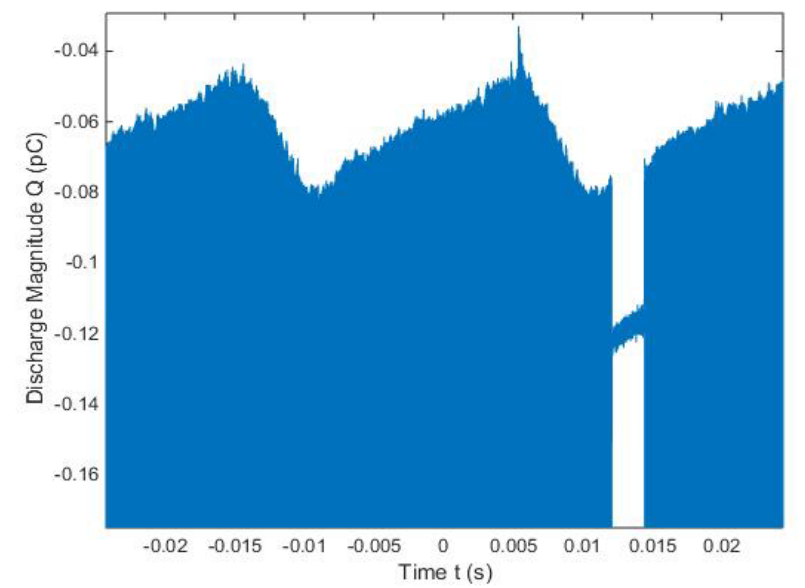

Figure 19. PD pulses recorded at the test object for a voltage of $-36.3 \mathrm{kV} \mathrm{dc}$ with $7.5 \%$ ripple.

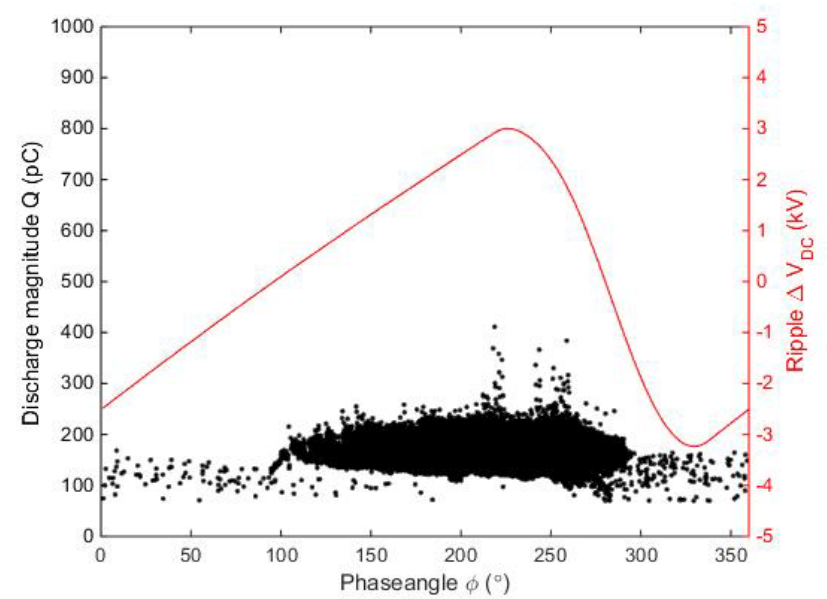

Figure 20. $\mathrm{Q}(\phi)$ and $\Delta \mathrm{V}_{\mathrm{DC}}(\phi)$ for a needle-plate arrangement with $30 \mathrm{~mm}$ electrode interspacing at $-39.5 \mathrm{kV}$ dc with a ripple of $7.5 \%$.

\section{CONCLUSION}

A precise treatment of the evolution of partial discharges and the resulting phase resolved pattern, when a negative dc voltage with a ripple of $7.5 \%$ is applied to a needle-plate arrangement with $30 \mathrm{~mm}$ electrode interspacing, is given.

The following patterns can be derived from corona inception to glow discharge inception:

1) The phase resolved pattern at corona inception voltage contains only of discharges which are limited to an area around the maximum of the applied voltage.

2 ) If the applied voltage is high enough that the inception voltage is reached throughout the whole curse of the voltage curve the resulting pattern follows the waveform of the applied voltage.

3) When the voltage reaches a level where space charges are dominant then low magnitude discharges start to follow the inverse of the voltage curve.

4) A shrinking of the pattern in the maximum of the applied voltage indicates the beginning transition from Trichel pulse discharges to glow discharges.

5) Disappearance of discharges in the voltage maximum, while discharges are still present near the minimum shows the presence of pulseless glow discharges. 
All of the patterns were recorded using a commercially available discharge measurement system without complex data post-processing or statistical analysis. This results in a plug and play-like test setup that is capable of evaluation dc $\mathrm{PD}$ in the same way as it is common for ac PD.

The unique attributes of each of the five patterns, enables a reliable identification of corona discharges and their evolution from Trichel pulse corona to glow discharges. Therefore, it was shown that corona driven by a dc voltage can for the first time be completely evaluated using a common PD recorder in combination with a PRPD analyzation while relying on the experience from ac PD.

\section{REFERENCES}

[1] R. Piccin, A. Mor, P. Morshuis, A. Girodet, and J. Smit, "Partial Discharge Analysis of Gas Insulated Systems at High Voltage AC and DC," IEEE Trans. Dielectr. Electr. Insul., Vol. 22, No. 1, pp. $218-228,2015$.

[2] S. Blufpand, A. R. Mor, P. Morshuis, and G. C. Montanari, "Partial Discharge Recognition of Insulation Defects in HVDC GIS and a Calibration Approach," IEEE Electr. Insul. Conf. (EIC), pp. 564-567, 2015.

[3] P. Morshuis, "Defects and interfaces at DC voltage," Int'l Sympos. Electr. Insulating Materials (ISEIM), pp. 517-523, 2011.

[4] P. Morshuis, A. Cavallini, D. Fabiani, G. C. Montanari, and C. Azcarraga, "Stress Conditions in HVDC Equipment and Routes to in Service Failure," IEEE Trans. Dielectr. Electr. Insul., Vol. 22, No. 1, pp. 81-91, 2015.

[5] T. Klueter, J. Wulff, and F. Jenau, "Measurement and statistical analysis of Partial Discharges at DC voltage," 48 Universities Int'l. Power Eng. Conf. (UPEC), pp. 1-5, 2013.

[6] P. Morshuis and J. J. Smit, "Partial Discharges at dc Voltage: Their Mechanism, Detection and Analysis," IEEE Trans. Dielectr. Electr. Insul., Vol. 12, no. 2, pp. 328-340, 2005.

[7] W. Si, J, Li, P. Yuan, and Y. Li Y, "Digital Detection, Grouping and Classification of Partial Discharge Signals at DC Voltage," IEEE Trans. Dielectr. Electr. Insul., Vol. 15, No. 6, pp. 16631674,2008

[8] T. Betz, T. Dezenzo, D. Sunaryadi and F. Radler, "Teilentladungsdetektion und Fehlererkennung in DC-Systemen: Neue Ansätze," ETG-Fachbericht, Vol. 144, 2014, Diagnostik elektrischer Betriebsmittel , Beiträge der 6. ETG-Fachtagung Berlin: VDE-Verlag, 2014.
[9] T. Dezenzo, T. Betz, and A. T. Schwarzbacher, "A New Method for the Evaluation and Recognition of Corona Under Direct Voltage Stress," $26^{\text {th }}$ Irish Signals and Systems Conf. (ISSC), pp. 1-6, 2015.

[10] E. Kuffel, W. S. Zaengl, and J. Kuffel, High Voltage Engineering: Fundamentals, 2nd ed. Oxford, Boston: ButterworthHeinemann/Newnes, 2000.

[11] P. Sattari, C. F. Gallo, G. S. P. Castle and K. Adamiak, "Trichel pulse characteristics - negative corona discharge in air," J. Phys. D: Appl. Phys., Vol. 44, No. 15, p. 155502, 2011.

[12] L. B. Loeb, A. F. Kip, G. G. Hudson, and W. H. Bennett, "Pulses in Negative Point-to-Plane Corona," Phys. Rev., Vol. 60, No. 10, pp. 714-722, 1941.

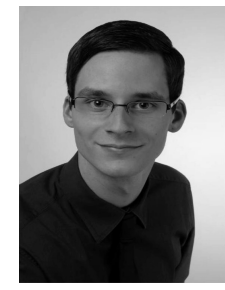

Tobias Dezenzo (S'16) was born in Offenbach am Main, Germany in 1987. He received the B. Eng. degree from the University of Applied Sciences Darmstadt, Germany in 2012, the M.Sc. degree from University of Applied Sciences Darmstadt, Germany in 2013. He is currently working toward the Ph.D. degree at Dublin Institute of Technology, Ireland. $\mathrm{He}$ is a teaching-fellow at University of Applied Sciences Darmstadt. His current research interests are in the field of partial discharges at de voltage.

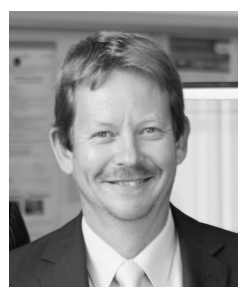

Thomas Betz received the Dr.-Ing. degree in 1997 from the Technical University of Darmstadt. He has 11 years industrial experience in development of high voltage gas-insulated switchgear, finally as head of development. In 2009 he joined the University of Applied Sciences in Darmstadt as professor for high voltage technology and power systems. He is member of VDE and Cigré. In this context he participated in the Cigré working group A3.27 about the impact of the application of Vacuum Switchgear at transmission voltages. The main research field is the defect prevention by partial discharge analysis and the recognition of failure causes in case of DC-applications.

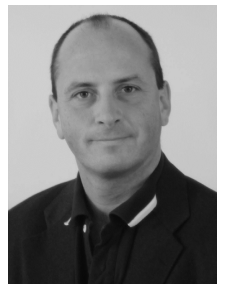

Andreas Schwarzbacher is a lecturer at the Dublin Institute of Technology, Ireland. He was awarded a degree in communications engineering by the industry financed University of Dieburg in Germany in 1995, a M.Sc. degree in computer science by the National University of Ireland, Maynooth in 2005 and a Ph.D. degree in electronics by Trinity College, University of Dublin, Ireland in 2001. Dr. Schwarzbacher has been a guest lecture in various universities and he is working for Engineers Ireland in the quality control of various degree programs. 